\title{
California Needs to Make Improvements in Guideline Implementation
}

\section{TO THE EDITOR:}

We are a large multi-specialty practice of Interventional Pain Management in California, treating a significant proportion of injured workers with chronic pain. As elaborated on by Manchikanti et al $(1,2)$, we have been observing the effects of misuse and abuse of flawed ACOEM Guidelines 2nd edition (3) that were adopted in 2004 as presumptively correct for purposes of utilization review by the California Department of Industrial Relations, Division of Workers Compensation (DWC).

Specifically, we have seen first hand how ACOEM guidelines have been cited by utilization reviewers and used as a cover for worker's compensation insurance carriers to deny medically reasonable and necessary treatment for injured workers with chronic pain.

Fortunately, reason has prevailed in California and the Division of Workers Compensation has considered and rejected the recently updated ACOEM Guidelines on Low Back Disorders (4) and Chronic Pain (5), and instead is incorporating language into its updated Medical Treatment Utilization Schedule from the Work Loss Data Institute's Official Disability Guidelines. The new MTUS Chronic Pain Medical Treatment Guidelines (6) have resulted from enlightened collaboration of DWC and a Medical Evidence Evaluation and Assessment Committee, which included input from qualified expert representatives in Interventional Pain Management. We believe these developments will result in better access to quality medical care and improved outcomes and overall lower costs for injured workers in California.

Francis X. Riegler, MD

Ray H. d'Amours, MD

Shahin A. Sadik, MD

Universal Pain Management

819 Auto Center Drive

Palmdale, CA 93551

E-mail: Friegler@upmgt.com

\section{References}

1. Manchikanti L, Singh V, Derby R, Helm $S$, Trescot AM, Staats PS, Prager JP, Hirsch JA. Review of occupational medicine practice guidelines for interventional pain management and potential implications. Pain Physician 2008; 11:271-289.

2. Manchikanti L, Singh V, Helm S, Trescot AM, Hirsch JA. A critical appraisal of 2007 American College of Occupational and Environmental Medicine (ACOEM) practice guidelines for interventional pain management: An independent review utilizing AGREE, AMA, IOM, and other criteria. Pain Physician 2008; 11:291-310.
3. Glass LS, Harris JS; American College of Environmental and Occupational Medicine (ACOEM). Occupational Medicine Practice Guidelines: Evaluation and Management of Common Health Problems and Functional Recovery of Injured Workers, Second Edition. OEM Press, Beverly Farms, 2004.

4. American College of Occupational and Environmental Medicine (ACOEM) Low Back Disorders. In Occupational Medicine Practice Guidelines: Evaluation and Management of Common Health
Problems and Functional Recovery of Injured Workers, Second Edition. OEM Press, Beverly Farms, 2007.

5. American College of Occupational and Environmental Medicine (ACOEM) Chronic Pain. In Occupational Medicine Practice Guidelines: Evaluation and Management of Common Health Problems and Functional recovery of Injured Workers, Second Edition. OEM Press, Beverly Farms, 2008.

6. www.dir.ca.gov/dwc/DWCPropRegs/ MTUS_regulations/MTUS_ChronicPainTreatmentGuideline.pdf 